\title{
Observations of Long-tailed Weasel, Mustela frenata, Hunting Behavior in Central West Virginia
}

\author{
Brian W. SMith ${ }^{1}$, Chris A. Dobony ${ }^{1}$, John W. Edwards ${ }^{1}$, And W. Mark Ford ${ }^{2}$ \\ ${ }^{1}$ Division of Forestry, West Virginia University, PO Box 6125, Morgantown, West Virginia 26506-6125 USA \\ ${ }^{2}$ USDA Forest Service, Northeastern Research Station, PO Box 404, Parsons, West Virginia 26287 USA
}

Smith, Brian W., Chris A. Dobony, John W. Edwards, and W. Mark Ford. 2003. Observations of Long-Tailed Weasel, Mustela frenata, hunting behavior in central West Virginia. Canadian Field Naturalist 117(2): 313-315.

Using infrared video-surveillance systems during 1999-2000, we observed attempts by two individual Long-tailed Weasels (Mustela frenata) to depredate female Ruffed Grouse (Bonasa umbellus) and their clutch of eggs. Neither female was captured despite Long-tailed Weasel attacks on multiple nights, but all eggs from one nest were either consumed or cached over a two-night period. Although Long-tailed Weasels have been shown to return quickly to areas of abundant prey, return visit behavior to locations where weasels were unsuccessful or only partially successful are poorly described.

Key Words: Ruffed Grouse, Bonasa umbellus, Long-tailed Weasel, Mustela frenata, nest predation, West Virginia.

Most reports of Long-tailed Weasel feeding behaviors have been anecdotal observations (Criddle and Criddle 1925; Errington 1936; Quick 1944; Mumford 1969; Muths 1998), feeding experiments in a laboratory setting (Quick 1951; Byrne et al. 1978; DeVan 1982), or indirectly inferred from live-trapping and telemetry studies (DeVan 1982). Regardless of method, success rates and specific predatory behavior are lacking for Long-tailed Weasels, especially on groundnesting birds. Our objective was to document the frequency of Long-tailed Weasel depredation of Ruffed Grouse nests, describe weasel behaviors recorded at the nest, and determine the outcomes of any visit by weasels to these nests.

\section{Study and Methods}

Our study was conducted at the Mead-Westvaco Wildlife and Ecosystem Research Forest (MWERF) located in Randolph County, West Virginia (38 $44^{\prime}$ N, 7958' W) from 1999-2000. Mead-Westvaco established the MWERF (3413 ha) in 1994 to study the impacts of industrial forestry on Appalachian ecosystems and ecological processes. Located in the unglaciated Allegheny Mountain and Plateau physiographic province, elevations range from $740 \mathrm{~m}$ to $1200 \mathrm{~m}$. Most of the MWERF contained 60-80 year-old secondgrowth stands that have been subjected to repeated diameter-limit harvests over the past two decades. A detailed description of the study area is provided in Dobony (2000).

During the nesting seasons (mid-April to early June) of 1999-2000, we used miniature infrared video cameras and time-lapse video recorder systems (Fuhrman Microcam2 camera + Fieldcam LCTLV time-lapse video recorder, Fuhrman Diversified, Seabrook, Texas) to monitor Ruffed Grouse nests (1999: $n=9 ; 2000: n$ $=11$ ). Our video systems recorded continuously over $24 \mathrm{~h}$ using standard T-160 videocassettes, but at 3:1 ratios of real time to video time (i.e., an $8 \mathrm{~h}$ videocassette recorded $24=\mathrm{h}$ of activity). Cameras recorded black-and-white images and emitted infrared light at
$950 \mathrm{~nm}$, a wavelength not visible to vertebrate species (R. Fuhrman, Fuhrman Diversified, Inc., personal communication). Video cameras, including integrated infrared emitters, were housed within a $32 \times 32 \times 60 \mathrm{~mm}$ aluminum casing. Cameras were attached to an articulating clamp-arm that was used to secure them to substrate near nests. Cameras were mounted within $1 \mathrm{~m}$ of nests because infrared emitters only had an effective range of $\leq 1 \mathrm{~m}$. We equipped each camera housing and articulating clamp-arm with a cloth camouflage sleeve, and we mounted cameras in the most inconspicuous locations possible. Connected by cable, the time-lapse recording system and a 12-volt battery (power source) were hidden from view $20 \mathrm{~m}$ from nests.

We changed batteries and videocassettes at each nest daily. We examined each videocassette upon return from the study area to check nest status (i.e., depredation, incubation, or hatched) or if any animals other than Ruffed Grouse had visited the nest during the 24-h period. If a depredation or visitation had occurred, we further analyzed videocassettes to reveal the identity of the predator or visitor, time and duration of visit, and outcome of the visit. Herein, we restrict our discussion to events involving Long-tailed Weasels.

\section{Results}

We recorded Long-tailed Weasels at two of 20 (10\%) video-monitored Ruffed Grouse nests: one in 1999 and one in 2000. In both years, Long-tailed Weasels visited each nest twice, with visits occurring on consecutive evenings/nights. Videotaped Long-tailed Weasels were not individually marked, and we were unable to determine if more than one individual weasel was involved in consecutive visits at each nest, or the sex of those observed. However, Long-tailed Weasels are known to sometimes return to potential food sources (DeVan 1982), and we assumed that the same individual weasel made consecutive visits to each Ruffed Grouse nest. Because annual survival of weasels is low (Fagerstone 1987) and the nests visited were farther apart $(>5 \mathrm{~km})$ than typical for a Long-tailed Wea- 
sel home range (DeVan 1982), it is unlikely the same weasel visited both grouse nests across both years.

In 1999, Ruffed Grouse female 151.503 (identified by radio-frequency) began incubating 12 eggs on 25 April. On 2 May, a Long-tailed Weasel attempted to prey upon this female at 01:49:00. The Long-tailed Weasel initially was seen walking on a downed log directly above (approximately $0.3 \mathrm{~m}$ ) the grouse, which remained motionless on the nest. After a brief pause, the Long-tailed Weasel jumped from the log onto the grouse's back. The female escaped the attack and moved just out of the camera's view. The Long-tailed Weasel remained at the nest bowl for a brief period, smelling the eggs within the nest and feathers surrounding the nest. The Ruffed Grouse occasionally could be seen trying to harass the Long-tailed Weasel away from the nest. The Long-tailed Weasel left the camera's view at 01:49:39 without taking eggs or further attempting to capture the nearby grouse.

On 3 May 1999, female 151.503's nest was visited again by a Long-tailed Weasel. The Long-tailed Weasel initially appeared at 03:43:46 and jumped from the downed log towards the grouse's head. Again, the grouse was able to escape attack by flushing from the nest. The Long-tailed Weasel subsequently smelled the eggs in the nest and then left the camera's view. This visit lasted only 8 seconds.

Female 151.503's nest was depredated on 20 May 1999; unfortunately, the camera had been removed on 18 May for another aspect of the study. Sign at the nest indicated that the marauder was a mammalian predator, but it was impossible to narrow it down to a particular species (i.e., nest appeared to have been visited by several species after depredation and all eggs were missing with only a few egg shell fragments remaining).

In 2000, Ruffed Grouse female 151.172 initiated incubation of 11 eggs around 2 May, and a video system was placed at her nest on 6 May. On 18 May, BWS (senior author) approached the area at approximately 08:00:00 to change the battery and videotape. A Ruffed Grouse flushed from the general location of the nest (females rarely, if ever, flushed from a nest upon approach to change equipment), indicating some other disturbance. Upon investigation through binoculars, BWS saw that the nest had been disturbed, finding seven eggs displaced approximately $4 \mathrm{~m}$ downhill. Six eggs were still intact and one had cracked upon impact with a rock. BWS could not find eggshell fragments or other signs of predation near the nest. BWS returned the six intact eggs to the nest to determine if the Ruffed Grouse or the predator would return to the nest for the remaining eggs.

When the videotape from 17/18 May was reviewed, it showed that a Long-tailed Weasel attempted to capture the grouse at 01:14:03 on 18 May. The Longtailed Weasel initially was seen walking on a portion of exposed tree root-wad directly above (approximate- ly $0.2 \mathrm{~m}$ ) the grouse, which remained motionless on the nest. The Long-tailed Weasel then leapt from the root toward the female. Female 151.172 appeared to fly away from the immediate area. The Long-tailed Weasel remained at the nest bowl, smelling eggs and feathers within the nest. It then began to smell the eggs actively, rolling seven of them out of the nest bowl with its nose. The Long-tailed Weasel finally consumed the contents of one egg on video, after several unsuccessful attempts at opening the egg. In doing so, the Longtailed Weasel curled into a tight ball (lying on its side) while holding the egg with all four feet. The Longtailed Weasel proceeded to rotate the egg until the egg apex was in its mouth. It eventually punctured the eggshell and began lapping the contents of the egg through the hole created in the egg's top. The remaining three eggs were moved to an area outside the camera's view; it is unknown whether these eggs were consumed or cached. The Long-tailed Weasel left the camera's view at 01:27:39.

On 18 May 2000, after we replaced the six eggs, presumably the same Long-tailed Weasel returned to the nest (although the grouse never returned). At 17:02:25, the Long-tailed Weasel entered the nest and proceeded to remove three eggs from the nest bowl and away from the camera's view. The Long-tailed Weasel left the camera's view for the final time at 17:11:19. The following day, we found two eggs cached under a root stem and leaves approximately $10 \mathrm{~cm}$ from the nest bowl. Another egg was cached under a downed $\log$ approximately $0.5 \mathrm{~m}$ from the nest. Its contents had been consumed.

\section{Discussion}

Given the disparity in body sizes (80-250 $\mathrm{g}$ for female Long-tailed Weasels and 160-450 g for males [Fagerstone 1987], and 450-650 g for female Ruffed Grouse [Rusch et al. 2000]), it is surprising that this small mustelid would attempt to capture an adult Ruffed Grouse. However, Long-tailed Weasels are rather opportunistic and generalized in their dietary habits and have been known to prey on animals larger than themselves (e.g., Cottontails [Sylvilagus sp.] and Snowshoe Hares [Lepus americanus]; Fagerstone 1987). Of particular interest in our findings was the difference between the outcomes of the attempted depredations; one Long-tailed Weasel appeared only interested in capturing the grouse, leaving the eggs unmolested whereas the other consumed or cached many of the eggs after failing to capture the nesting female. Unfortunately, we were unable to determine what type of mammalian predator returned to destroy female 151.503's nest.

Ground-nesting birds and their eggs are thought to compose only a small portion of Long-tailed Weasel diets (Fagerstone 1987). For example, 11\% of destroyed Blue-winged Teal (Anas discors) nests were depredated by weasels (Teer 1964), only $12 \%$ of fecal 
samples in Iowa contained feathers or egg fragments (Errington 1936), and in only two of four areas where weasel diets were sampled were avian remains found in fecal samples (Simms 1979). Bump et al. (1947) reported that approximately $11 \%$ (49 of 463) of Ruffed Grouse nests were destroyed by weasels but believed this was probably a conservative estimate because another 40 (9\%) depredated nests were attributed to either weasel or fox.

Despite how infrequently avian remains appear in Long-tailed Weasel diets, our videography shows that they can be very disruptive to ground-nesting birds. Continual flushing of an incubating bird, regardless of whether the Long-tailed Weasel captures the bird or removes any eggs, likely has a negative impact on survival of the young. Moreover, extended absence from the nest can expose eggs to excessive cooling or other predators. In addition to the egg caching we captured on video, we have witnessed entire Ruffed Grouse broods lost to predation in a $24 \mathrm{~h}$ period. At least one was very suggestive of Long-tailed Weasel predation (Dobony 2000, B. Smith, unpublished data). Therefore, it appears that Long-tailed Weasels can be considered potential predators (direct effects) and nest disrupters (indirect effects) of Ruffed Grouse and thus potentially could be influencing Ruffed Grouse productivity in the Appalachian Mountain region. Ruffed Grouse densities are lower in the southern portion of its range than in more northern reaches (Bump et al. 1947), potentially because of lower productivity at southern latitudes (Bergerud 1988). Dobony et al. (2001) reported nest depredation to be a primary factor influencing Ruffed Grouse nest success in West Virginia.

\section{Acknowledgments}

Our study was conducted as part of the Appalachian Cooperative Grouse Research Project and was supported in part by West Virginia Division of Natural Resources (Pittman-Robertson Federal Aid in Wildlife Restoration Project W-48-R) and the Division of Forestry, West Virginia University. We thank the Richard King Mellon Foundation and The Ruffed Grouse Society for additional funding, Mead-Westvaco Corporation for logistical support, and the West Virginia Cooperative Fish and Wildlife Research Unit for use of their video surveillance systems. Additionally, we thank T. Allen, N. Herbert, J. Johnson, T. Olexa, and S. Sutton for assistance with field work.

\section{Literature Cited}

Bergerud, A. T. 1988. Mating systems in grouse. Pages 439-472 in Adaptive strategies and population ecology of northern grouse. Edited by A. T. Bergerud and M. W. Gratson. University of Minnesota Press, Minneapolis.

Bump, G., R. W. Darrow, F. C. Edminster, and W. F. Crissey. 1947. The ruffed grouse: life history, propagation, management. New York State Conservation Department. 915 pages.

Byrne, A., L. L. Stebbins, and L. Delude. 1978. A new killing technique of the long-tailed weasel. Acta Theriologica 23: 127-131.

Criddle, N., and S. Criddle. 1925. The weasels of southern Manitoba. The Canadian Field-Naturalist 39: 142-148.

DeVan, R. 1982. The ecology and life history of the longtailed weasel (Mustela frenata). Dissertation, University of Cincinnati, Cincinnati, Ohio, USA. 300 pages.

Dobony, C. A. 2000. Factors influencing ruffed grouse productivity and chick survival in West Virginia. M.S. thesis, West Virginia University, Morgantown. 97 pages.

Dobony, C. A., J. W. Edwards, W. M. Ford, and T. J. Allen. 2001. Nesting success of ruffed grouse in West Virginia. Proceedings of the Annual Conference of the Southeastern Association of Fish and Wildlife Agencies 55: 456-465.

Errington, P. L. 1936. Food habits of a weasel family. Journal of Mammalogy 17: 406-407.

Fagerstone, K. A. 1987. Black-footed ferret, long-tailed weasel, short-tailed weasel, and least weasel. Pages 549573 in Wild furbearer management and conservation in North America. Edited by M. Novak, J. A. Baker, M. E. Obbard, and B. Malloch. Ontario Trappers Association, North Bay, Ontario, Canada.

Mumford, R. E. 1969. Long-tailed weasel preys on big brown bats. Journal of Mammalogy 50: 360.

Muths, E. 1998. An observation on caching of prey by a long-tailed weasel (Mustela frenata). The Southwestern Naturalist 43: 106.

Quick, H. F. 1951. Notes on the ecology of weasels in Gunnison County, Colorado. Journal of Mammalogy 32: 281290.

Rusch, D. H., S. DeStefano, M. C. Reynolds, and D. Lauten. 2000. Ruffed grouse (Bonasa umbellus). In The Birds of North America (515). Edited by A. Poole and F. Gill. The Birds of North America, Inc., Philadelphia, Pennsylvania.

Simms, D. A. 1979. North American weasels: resource utilization and distribution. Canadian Journal of Zoology 57: 504-520.

Teer, J. G. 1964. Predation by long-tailed weasels on eggs of blue-winged teal. Journal of Wildlife Management 28: 404-406.

Received 21 June 2002

Accepted 5 November 2003 